\title{
ESTADO, INSTITUIÇÕES E DESENVOLVIMENTO: O MODELO COREANO EAINTERPRETAÇÃO DA CRISE ASIÁTICA
}

\author{
Alexandre Queiroz Guimarães
}

\begin{abstract}
RESUMO
O presente artigo insere-se em uma linha voltada a investigar as relações entre as instituições, o Estado e o desempenho econômico. Tem como objeto central o estudo dos Estados Desenvolvimentistas (Developmental States), isto é, estados intervencionistas que desempenharam papel central nas estratégias de desenvolvimento de alguns países. A despeito de inúmeras análises históricas sobre essas experiências, o tema é considerado controverso e muitos economistas relutam em aceitar que tais estados tiveram uma contribuição positiva. O artigo lida, portanto, com um tema muito caro à ciência econômica desde os seus primórdios, a relação entre o Estado e o mercado e seus impactos sobre a "riqueza das nações". O presente artigo pretende contribuir para essa temática por meio de uma crítica às análises mais abstratas voltadas a interpretar o modelo asiático e a crise de 1997. Identificando uma falha metodológica nessas análises, argumenta-se que a crise não pode ser deduzida de eventuais fraquezas institucionais do modelo sul coreano. As características institucionais, incluindo o Estado desenvolvimentista e os grandes grupos empresariais, foram variáveis centrais para explicar o grande êxito alcançado pela Coréia do Sul nas décadas que se seguiram a 1960. Nesse sentido, as dificuldades dos anos 1990 devem ser interpretadas como resultado de um processo apressado de liberalização e desregulamentação econômica, implementado antes que uma nova estrutura de regulação estivesse pronta para substituir as formas de coordenação vigentes no período anterior. Ao recusar certas interpretações da crise, o artigo enfatiza a importância de reconhecer as especificidades institucionais dos paises e a existência de diferentes tipos de capitalismo. O caso sul coreano, assim como o japonês, ilustra um modelo de capitalismo em que o Developmental State desempenhou um papel muito ativo, constituindo-se em uma variável fundamental para explicar o grande sucesso obtido pela estratégia de desenvolvimento nesses países.
\end{abstract}

PALAVRAS-CHAVE: Coréia do Sul; developmental state; modelos de capitalismo; crise asiática; instituições; desenvolvimento.

\section{INTRODUÇÃO}

Este artigo enquadra-se em uma linha que focaliza as diferenças institucionais entre os países e os impactos daí decorrentes em seu desempenho econômico. Optou-se por empregar como estudo de caso a Coréia do Sul, um país relativamente atrasado nos anos 1950 que obteve grande êxito em sua estratégia de industrialização, modificando sua inserção na divisão internacional do trabalho ${ }^{1}$. Trata-se de um modelo institucional diferente, marcado por um Estado muito intervencionista, por uma organização empresari-

\footnotetext{
1 Em síntese, um dos poucos países em desenvolvimento considerado um caso de sucesso na estratégia de desenvolvimento adotada no pós-guerra.
}

al não convencional e pela constituição de vários arranjos informais que visavam suprir a ausência das instituições formais características do capitalismo ocidental.

No intuito de melhor refletir sobre os fatores em questão, passando pelas razões do sucesso e pelas causas da forte crise econômica dos anos 1990, inicia-se apresentando e comentando um rico e bem fundamentado livro sobra a crise de 1997 na Coréia do Sul, The Korean Economy Beyond the Crisis, organizado por Chung e Eichengreen (2004). Trata-se de um livro que explica a crise a partir do que os autores consideram as inconsistências institucionais do capitalismo coreano, levantando pontos que considero essenciais para a análise (e a crítica) desenvolvida a seguir. A decisão de efetuar uma apresentação 
de pontos-chaves do livro visa suscitar aspectos que muito enriquecem a análise do modelo de capitalismo coreano. No entanto, pretende-se, também, empreender uma crítica considerada decisiva para o estudo da economia política comparada. O livro organizado por Chung e Eichengreen, ao sintetizar muitos pontos do receituário liberal convencional ${ }^{2}$, comete um erro metodológico que distorce muitas de suas conclusões. Nesse sentido, o artigo toma também a forma de uma crítica metodológica, indicando as falhas de análises que aplicam acriticamente teorias econômicas abstratas a experiências concretas de desenvolvimento. Como ponto correlato, mas decisivo, o artigo destaca a necessidade de se considerar as diferenças institucionais que marcam as economias, recusando a noção de que existe uma forma superior de organização do capitalismo. As seções finais do artigo qualificam e exemplificam esse ponto, destacando a importância das instituições coreanas para o sucesso de seu modelo de desenvolvimento.

A próxima seção apresenta aspectos centrais da interpretação ortodoxa (liberal) do modelo coreano e da crise. A seção 3 apresenta traços da reposta coreana à crise. A seção 4 desenvolve uma crítica metodológica a análises ortodoxas de economia política comparada. A seção 5 destaca o papel das diferenças institucionais entre os países, enquanto as seções 6 e 7 exploram duas importantes particularidades do modelo coreano: os grupos empresarias e o Estado Desenvolvimentista. Enfim, a seção 8 conclui, reavaliando a crise à luz das particularidades institucionais do capitalismo coreano.

\section{A ANÁLISE OFICIAL DO MODELO ASIÁ- TICO E DA CRISE COREANA}

O livro organizado por Chung e Eichengreen faz uma abrangente exposição da crise econômica que atingiu a Coréia do Sul em 1997, avaliando as causas, a resposta imediata, as reformas

\footnotetext{
2 Não há aqui nenhuma conotação depreciativa nas menções a ortodoxo, convencional ou liberal. Existe uma linha dominante no estudo da Economia que muito contribui para a capacidade dessa ciência entender seu objeto. No entanto, o paradigma dominante, ao empreender uma abordagem eminentemente 'dedutivista' e ao desconsiderar certos aspectos histórico-institucionais, falha na interpretação de algumas experiências de desenvolvimento. As implicações podem ser significativas, dado que a interpretação tende a balizar políticas de ajustamento.
}

implementadas e os impactos sociais da crise. Um ponto central do argumento, compartilhado por vários colaboradores, é que a crise resultou de contradições internas ao modelo, que, ofuscadas durante o período de rápido crescimento, vieram à tona com o amadurecimento da economia e com a maior abertura nos anos 1990. Em outras palavras, as elevadas taxas de crescimento alcançadas entre 1960 e $1990^{3}$ ocorreram a despeito de uma série de dificuldades e contradições presentes na organização da economia. Argumenta-se que o crescimento não teve nada de excepcional, sendo explicado pela rápida acumulação de fatores produtivos, pela abundante oferta de capital humano e pela importação de idéias e práticas de países mais avançados. Tratava-se, segundo os autores, dos primeiros estágios do crescimento, em que o capital é escasso e tem produtividade alta, havendo, portanto, muitas oportunidades lucrativas de investimento.

Os autores reconhecem os méritos da política econômica: ao contrário do ocorrido em muitos países em desenvolvimento, a política macroeconômica manteve a inflação em limites aceitáveis e as taxas de juros positivas, além de garantir uma taxa de câmbio favorável às exportações. Entretanto, os autores reiteram que o processo foi marcado pela acumulação de diversas distorções. A estrutura empresarial, caracterizada pela formação de grandes grupos muito diversificados (os chaebols), destacava-se pela falta de boas regras de governança corporativa e de mecanismos que protegessem os interesses dos acionistas minoritários. Assim, o arranjo propiciava excessiva autonomia para os principais acionistas e gerentes. Ao mesmo tempo, uma estrutura de ações cruzadas dentro dos grupos ampliava a influência dos acionistas principais, que exerciam um controle muito mais que proporcional à respectiva participação no capital do grupo. Dessa forma, o arranjo implicava uma fusão entre propriedade e controle, que, no intuito de sustentar subsidiárias pouco eficientes, acabava também por prejudicar aquelas mais competitivas.

Uma segunda fonte de distorções teria sido produzida pela relação muito próxima e arbitrária estabelecida entre o Estado e os grupos empresa-

3 Entre 1960 e 1990, o Produto Interno Bruto per capita da Coréia do Sul, em termos reais, aumentou 28,67 vezes. Dados da Penn World Table (2009). 
riais. O Estado coreano procurou, por meio de uma estrutura de incentivos e punições, direcionar os investimentos para setores considerados estratégicos. Tal comportamento teria favorecido o "risco moral", ampliando a propensão dos empresários a engajarem-se em operações arrojadas, na confiança de que seriam socorridos em caso de dificuldades.

Os capítulos do livro mostram que fortes distorções marcavam também o sistema financeiro e as práticas de concessão de empréstimos. Faltavam aos bancos bons critérios de avaliação de risco, o que os levava a balizar seus empréstimos segundo as garantias que recebiam das empresas. Assim, os bancos valorizavam excessivamente o tamanho das empresas, direcionando grande parte de seus recursos para os chaebols. Em todo o processo, o Estado exercia forte influência sobre a alocação dos recursos financeiros. Como resultado, o arranjo contribuía para a instabilidade do sistema financeiro, uma vez que os bancos concentravam seus empréstimos em poucas empresas. As empresas, por sua vez, endividavam-se excessivamente e, no afã de crescer rapidamente, realizavam muitos investimentos com lucratividade duvidosa.

Por trás dessa situação, salientava-se a falta de uma estrutura de regulação minimamente efetiva. Não era exigido das empresas ou dos bancos o cumprimento de critérios internacionais de contabilidade e transparência, de forma que os prejuízos das empresas e a proporção de empréstimos duvidosos não eram divulgados, comportamento que indicava a importância que se conferia às práticas informais e aos laços pessoais.

Em síntese, faltavam uma boa estrutura de direitos de propriedade, boas regras de governança corporativa e bons mecanismos de regulação. Esses fatores eram "substituídos" por relações informais, em um processo em que o Estado exercia muita influência. Segundo Eichengreen e Chung (2004), em uma fase inicial, em que mobilizar capital e investir constituíam preocupações mais importantes do que inovar, essa estrutura favoreceu altas taxas de crescimento. No entanto, as distorções acumularam-se, como indicado pela queda da lucratividade e pela fragilidade do sistema financeiro. Segundo Eichengreen e Chung (2004, p. 6), a lucratividade média dos trinta maiores chaebols, que era de $10 \%$ em meados dos anos 1980 , teria caído para $6 \%$ no início dos anos
1990 e menos de 3\% em 1996. Por sua vez, a relação dívida-ações (debt-equity) dos trinta maiores chaebols atingiu 348\% em 1995 e 519\% em 1997 (JOH, 2004, p. 203).

Enquanto havia oportunidades muito lucrativas de investimento, as distorções e dificuldades ficavam ofuscadas. $\mathrm{O}$ problema viria à tona no momento de transição para um crescimento mais intensivo, mais dependente da produtividade e da capacidade de inovar. Esse momento, segundo os autores, teria sido atingido nos anos 1980, caracterizado também pela mudança de eixo da indústria pesada para setores mais tecnológico-intensivos. Foi nesse contexto que se acumularam também pressões para a liberalização da economia e para a abertura da conta de capitais.

Um marco na trajetória coreana foi o movimento de liberalização financeira ocorrido nos anos 1990. Um ponto destacado por Eichengreen e Chung (2004) é a influência de fatores internos no processo de abertura da conta de capitais. A pressão internacional foi forte, especialmente dos Estados Unidos ${ }^{4}$, culminando no aprofundamento de exigências que se seguiu à decisão coreana de tornar-se membro da Organização para Cooperação e Desenvolvimento Econômico (OECD), em 1993. No entanto, a forma como foi conduzida a abertura indica a busca por fontes alternativas de recursos, condição, naquele momento, para preservar as altas taxas de crescimento em uma economia com lucratividade declinante ${ }^{5}$. Daí um processo de liberalização que se centrou em facilitar o acesso a empréstimos externos pelos bancos coreanos, ao mesmo tempo em que conservava fortes restrições à atuação estrangeira no mercado de títulos e de ações e ao investimento direto externo.

Como resultado imediato, a liberalização favoreceu o fluxo de recursos externos e o aumento do investimento. Deve-se destacar, no entanto, que essas medidas não resolviam um problema cuja

4 A base para a liberalização financeira ocorrida em 1993 foi determinada em conversas bilaterais com os EUA em 1992 (CHANG, PARK \& YOO, 1998).

5 Deve-se destacar que uma economia caracterizada por empresas muito endividadas necessitava que o crescimento econômico reproduzisse-se sob o risco de provocar uma grande onda de inadimplência. Essa necessidade constrangia a ação estatal, ajudando a explicar a direção das reformas. 
raiz, segundo os autores, estava na lucratividade declinante, na ineficiência e no alto grau de endividamento. Além disso, um processo de liberalização financeira realizado sem uma estrutura prévia de regulação contribuiu para o forte endividamento de curto prazo em moeda estrangeira, amplificando a fragilidade financeira da economia, agora também vulnerável a variações nas taxas de câmbio e às expectativas dos investidores estrangeiros.

A liberalização, deve-se destacar, representou um abalo em vários pontos que marcavam o modelo coreano, reduzindo a importância das práticas de direcionamento de crédito e de outras formas de intervenção. Ao mesmo tempo, os credores internacionais passaram a demandar melhor monitoramento das aplicações, sinalizando que maior atenção teria de ser dada à lucratividade. Tais exigências não passaram despercebidas, mas a possibilidade de reforma chocava-se com a resistência dos chaebols e com a magnitude das dificuldades financeiras, que exigiam mudanças profundas. Às vésperas da crise, a situação financeira deteriorou-se, com a triplicação do número de empréstimos podres (non performing loans) entre dezembro de 1996 e dezembro de 1997, tendo atingido 13\% do PIB em março de 1998 (PARK \& CHOI, 2004, p. 52-53).

Ao mesmo tempo, a situação externa agravouse pela deterioração do balanço de pagamentos, influenciada pela desvalorização prévia da moeda chinesa (em 1993) e pelos efeitos da crise econômica japonesa. O agravamento da situação exigia, portanto, resposta rápida do governo, mas este estava paralisado e incapacitado de agir. Em junho de 1997, o governo reagiu à crise do importante grupo Kia com complacência, estatizando-o e sinalizando para o "risco moral" (idem, p. 59). Tal resposta sinalizou para a possibilidade de outros casos similares, o que contribuiu para deteriorar a confiança dos investidores na economia coreana.

\section{A RESPOSTA À CRISE E AS PRINCIPAIS REFORMAS}

A crise foi deflagrada na Tailândia e, uma vez que as dificuldades eram compartilhadas, rapidamente espalhou-se para outros países da região. $\mathrm{Na}$ Coréia, levou à quebra de seis dos trinta maiores chaebols, enquanto $40 \%$ das empresas foram consideradas insolventes, incapazes sequer de pagar os juros (EICHENGREEN \& CHUNG, 2004, p. 12; JOH, 2004, p. 194). O fato de os bancos estrangeiros reagirem exigindo o pagamento rápido das dívidas apenas contribuiu para a velocidade do contágio.

Eichengreen e Chung (2004) avaliam positivamente a resposta macroeconômica à crise. Ao contrário de críticos, como o prêmio Nobel Joseph Stiglitz, que culpam o Fundo Monetário Internacional (FMI) por ter exigido uma política de juros muito altos em um país que não tinha problemas fiscais, os autores argumentam que muito pior que o aumento dos juros foi a desvalorização do câmbio, dado o impacto que teve no forte endividamento em moeda estrangeira. $\mathrm{O}$ argumento é que, embora uma política de liquidez mais folgada evitasse quebras e falências, teria, por outro lado, dificultado a rolagem das dívidas com os bancos estrangeiros.

Os impactos econômicos e sociais da crise foram consideráveis. Em 1998, o PIB (Produto Interno Bruto) caiu 7\%, acompanhado da demissão de um milhão de pessoas apenas na construção civil e na indústria (CHUNG, 2004, p. 33; CHOI \& KIM, 2004, p. 224). A força de trabalho caiu em cinco pontos percentuais e apenas recuperou o nível anterior à crise dois anos depois. As demissões atingiram, fundamentalmente, os trabalhadores de baixa escolaridade e também aqueles das pequenas empresas. Como conseqüência, o número de pobres aumentou de seis milhões em 1997 para dez milhões em 1998, havendo deterioração na distribuição de renda, redução da classe média e aumento da polarização social (LEE, 2004; CHOI \& KIM, 2004).

No entanto, a recuperação foi rápida, com crescimento de 10,7\% em 1999 e de 9\% em 2000, favorecida pela desvalorização do câmbio e pela retomada das exportações ${ }^{6}$. Também, o aumento dos gastos do governo e o estímulo ao crédito ao consumidor contribuíram sensivelmente para essa recuperação. Em 1998, o governo gastou 1,4 trilhões de won em obras públicas, gerando 400 mil empregos. Em 1999, os gastos foram de 2,3 trilhões de won, gerando 380 mil postos de trabalho (CHOI \& KIM, 2004, p. 223). O governo também aumentou a cobertura do seguro desemprego e a proporção de trabalhadores cobertos subiu de $33 \%$ para $70 \%$ (JUN, 2004, p. 122).

\footnotetext{
6 O que contribuiu para reverter um deficit na balança comercial de US\$ 8,2 bilhões em 1997 para um superavit de US\$ 40 bilhões em 1998 (CHUNG, 2004).
} 
A crise, ao expor a gravidade dos problemas e ao enfraquecer os chaebols, deflagrou uma série de reformas. O governo despendeu grande montante de recursos para re-escalonar empréstimos podres, socorrer bancos e prover o pagamento de seguros. Alguns bancos foram incorporados pelo governo, enquanto outros foram fechados. O número de bancos reduziu-se de 26 em 1997 para 15 no final de 2001. Houve também redução no número de empréstimos podres, que caiu de $14 \%$ do total de empréstimos em 1998 para 4\% em 2001 (EICHENGREEN \& CHUNG, 2004, p. 13). O governo passou a exigir dos bancos maior cautela na concessão e classificação de empréstimos, além de maior diversificação das aplicações, obtendo sucesso ao torná-los mais preocupados com o risco. Outra meta consistiu em reduzir a relação dívida-ações, acreditando que o estabelecimento de uma meta de $200 \%$ levaria os chaebols a venderem subsidiárias ineficientes e/ou emitir novas ações.

O governo criou uma agência independente, $o$ Financial Supevisory Council (FSC), que assumiu grande poder para reestruturar os grupos empresariais e o sistema financeiro. As autoridades indicaram também a disposição de incentivar o mercado de capitais, além de adotar medidas para facilitar a entrada de capital estrangeiro. Outra orientação foi reformular os grupos empresariais, pressionando os chaebols a concentraremse nos setores em que tinham maior eficiência. $\mathrm{O}$ principal grupo, o Hyundai, foi desmembrado em grupos menores e 16 chaebols foram fechados, incluindo o segundo maior grupo, o Daewoo. Tais medidas foram muito importantes ao sinalizarem para os demais grupos que os tempos haviam mudado. Entretanto, os impactos sociais da quebra do Daewoo foram tão grandes que tornaram o governo relutante em enfrentar casos similares (CHUNG, 2004, p. 37) 7 .

Outra direção foi a adoção de mudanças nas regras de governança corporativa, procurando enfraquecer os acionistas maiores e aumentar a participação e a capacidade de monitoramento por parte dos acionistas minoritários ${ }^{8}$. Em 1998, a

\footnotetext{
7 Quando, em 2000, decidiu pela liquidação de 52 companhias, deixou de fora algumas firmas grandes que apresentavam sérias dificuldades financeiras.

8 A legislação na Coréia restringia significativamente a possibilidade e a efetividade da participação de acionistas
}

Bolsa de Valores da Coréia passou a exigir que as empresas tivessem pelo menos um diretor externo, estabelecendo uma meta de 25\% para 1999. O governo, por sua vez, adotou medidas para fortalecer os interesses dos acionistas minoritários, reduzindo de $1 \%$ para $0,01 \%$ a proporção mínima das ações para o investidor ter alguma representação. O governo passou também a exigir a adoção de padrões internacionais de contabilidade, a emissão de relatórios periódicos pelas empresas e a contratação de um número mínimo de auditores externos (JOH, 2004, p. 213). Outras medidas incluíram a proibição de práticas de subsídios e garantias cruzadas dentro dos chaebols e a liberação da possibilidade de fusões e aquisições hostis.

Houve, portanto, avanços na obtenção de uma estrutura empresarial menos concentrada, de relações mais transparentes e de um modelo econômico mais sensível aos sinais de mercado. Entretanto, Eichengreen e Chung (2004) destacam que algumas medidas foram perfunctórias, enquanto outras foram insuficientes, de forma que os fatores responsáveis pelo colapso de 1997 não foram eliminados. Entre os limites, destaca-se o não fechamento de alguns chaebols e de alguns bancos em situação precária. A reestruturação corporativa foi também considerada tímida, dado que a estrutura de posse ficou intocada e o controle das famílias em alguns chaebols aumentou ${ }^{9}$. Segundo os autores, os acionistas minoritários ainda têm influência reduzida, há pouco controle sobre os gerentes e existem dúvidas em relação à independência dos gerentes externos. Criticam também a preservação da estrutura de ações cruzadas e a falta de uma legislação que facilite a realização de fusões, aquisições e transferência de propriedade

que tivessem menos de $5 \%$ da propriedade, enquanto eram raros os board de diretores que exerciam de fato monitoramento sobre os gerentes. O ponto defendido por Joh (2004) é que, em economias com governança corporativa mais avançada, as empresas em que os gerentes levam em conta seus próprios interesses à custa da empresa tendem a quebrar e ser expulsas do mercado. Na Coréia, no entanto, isso não ocorria devido à estrutura de ações cruzadas, ao acesso das firmas ao crédito e à proibição a aquisições hostis. Segundo Joh (idem, p. 206), a falta de mecanismos para expulsar as firmas ineficientes prejudicava o processo de "destruição criativa", comprometendo a produtividade e a eficiência do sistema.

9 Além disso, alguns chaebols aumentaram o número de subsidiárias, ocorrendo também aumento de participação desses grupos nas vendas de alguns setores. 
no caso de empresas seriamente endividadas. Em síntese, os autores consideram que há ainda grande atraso em termos de transparência e que se avançou pouco na criação de mecanismos para a expulsão de firmas ineficientes (idem; HAHM, 2004). ${ }^{10}$

Outra crítica destacada pelo livro é que se preservaram a alta discrição e a excessiva capacidade de intervenção da burocracia. Isso é bem ilustrado pelo padrão de intervenção do Financial Supervisory Council e pelos "acordos" adotados para reduzir a diversificação dos chaebols. Esses foram centrados na velha combinação de carrot $\mathrm{e}$ stick, com a concessão de incentivos para as empresas que seguissem as direções do governo e a restrição do acesso ao crédito para aqueles que recusassem. Nesse processo, coube ao FSC decidir sobre a definição dos setores em que os chaebols deveriam atuar e de quais deveriam abrir mão. Para os autores, o Estado continuava tomando decisões que não lhe cabiam, dado que seu papel deveria ser o de definir e fazer cumprir as regras, cabendo ao mercado a tarefa de selecionar os mais aptos (EICHENGREEN \& CHUNG, 2004; CHUNG, 2004, p. 40).

\section{INSUFICIÊNCIAS DA INTERPRETAÇÃO: \\ FALHA METODOLÓGICA E VÍCIO RICARDIANO}

Os artigos do livro empreendem uma rica descrição de vários aspectos relacionados à crise, detalhando a influência de algumas dificuldades internas ao modelo coreano para a ocorrência e para a gravidade da crise ${ }^{11}$. No entanto, a interpretação que atribuem ao modelo coreano apresenta algumas deficiências sérias, estando muitas conclusões centradas em uma aplicação acrítica e indevida de preceitos da teoria econômica (e do institucionalismo econômico) para a realidade coreana. Dá-se, por exemplo, grande importância ao dilema principal-agente, que é considerado cen-

\footnotetext{
10 Segundo Joh (2004, p. 205), a legislação não favorece a liquidação dos devedores, enquanto os procedimentos de falência tendem a demorar muitos anos. Em 1997, dos 17 mil casos de insolvência apenas 490 foram à corte, tendo ocorrido apenas 38 liquidações.

11 Deve-se lembrar que crises similares ocorreram algumas vezes nas décadas anteriores, tendo sido a combinação de fontes de fragilidade internas com os elementos externos introduzidos pela liberalização financeira que explicam a magnitude da crise de 1997 (WOO-CUMINGS, 1999).
}

tral para entender as dificuldades financeiras das empresas. Entretanto, apesar de indicações de dificuldades com algumas subsidiárias dos chaebols, o livro não traz evidências de que os problemas foram resultado da ação de gerentes pouco comprometidos com os interesses das empresas. Pelo contrário, é possível encontrar, em uma série de exemplos e indicadores, evidências de eficiência das firmas coreanas, muito bem sucedidas na capacidade de capturar segmentos do mercado internacional. Um erro similar ocorre no que diz respeito à avaliação do Estado e do seu papel no modelo de desenvolvimento. A análise do livro traz implícita a idéia do Estado como um conjunto de indivíduos buscando capturar rendas, fonte, portanto, de clientelismo e "risco moral". Em face dessa caracterização, as recomendações passam por reduzir ao máximo sua interferência e por facilitar a seleção por parte do mercado.

Não se pretende aqui escolher um dos lados naquilo que se considera uma ultrapassada e saturada controvérsia entre Estado e mercado. No entanto, é necessário destacar que essa dicotomia está fortemente presente em análises mais ortodoxas da economia política, contribuindo para um diagnóstico errado da crise asiática e das potencialidades do modelo asiático. É inquestionável o papel do mercado como princípio alocador de recursos, estando o sucesso coreano também ancorado na preservação do bom funcionamento dos mecanismos de mercado ${ }^{12}$. Reconhecer isso, no entanto, não implica desconsiderar o papel do Estado, ou igualar sua interferência à busca de rendas (rent seeking) e ineficiência. O Estado coreano foi muito atuante, sendo fundamental a atuação do "Estado Desenvolvementista" (Developmental State) - a despeito de algumas armadilhas e dificuldades -, para a transformação da Coréia em um país desenvolvido econômica e tecnologicamente, capaz de controlar importantes nichos do mercado mundial (WORLD BANK, 1993; EVANS, 2004; KOHLI, 2004; CHANG, 2006).

Portanto, encontra-se presente nas críticas tanto à organização empresarial quanto à atuação do Estado uma inconsistência metodológica que é resultado da aplicação, sem as devidas mediações,

12 Como destacado, o governo preservou bons fundamentos e evitou distorções que, em outros países, tiveram conseqüências negativas. 
das teorias abstratas do Institucionalismo Econômico e da Escolha Pública a uma experiência concreta de desenvolvimento. Percebem-se, portanto, ecos do debate metodológico ocorrido no século XIX entre a Economia Marginalista e a Escola Histórica Alemã. Não se trata, é claro, de contrapor a teoria econômica à história econômica, mas de destacar a necessidade de combinar as disciplinas, prestando atenção às particularidades institucionais do país em questão.

Revela-se, portanto, nas interpretações mais ortodoxas da crise asiática a presença de uma inconsistência metodológica batizada por Schumpeter de vício ricardiano ${ }^{13}$. Por trás dessa interpretação, encontra-se a tentativa de transportar para outros países instituições e estruturas do capitalismo norte-americano. Escapa, portanto, ao argumento liberal que o inconteste sucesso do modelo coreano deveu-se a traços institucionais característicos desse tipo de capitalismo, destacando-se o tipo de organização empresarial, a interação entre bancos e empresas, e as relações entre Estado e grupos empresariais. Isso não implica negar algumas distorções apontadas acima, mas reconhecer que, em um contexto específico, essas foram compensadas por outras formas de coordenação que muito contribuíram para o crescimento econômico e para o bem sucedido processo de convergência.

Em síntese, ao tentar encaixar o caso coreano nos preceitos da teoria econômica, a análise ortodoxa subestima as fontes de eficiência e os resultados alcançados. Os modelos neoclássicos de crescimento acertam quando argumentam que existem fatores que ajudam a entender por que países mais pobres tendem a crescer a taxas mais rápidas. No entanto, ao tentar encaixar casos reais no modelo, procurando explicar e associar casos como o coreano meramente a uma fase de "crescimento extensivo", simplifica-se equivocadamente a análise, desconsiderando os fatores que ajudam a explicar um grau de sucesso que foi ra-

13 Vício ricardiano é a tentativa de aplicar, acriticamente, considerações extraídas de modelos abstratos para realidades empíricas, desconsiderando que existem considerações de outra ordem e, mesmo, contingências que afetam a realidade concreta e as políticas em questão. David Ricardo cometeu este erro ao usar sua teoria da renda da terra, cheia de abstrações, para defender a abolição das Corn Laws. Ver Silveira (1991). ramente replicado por outras experiências de desenvolvimento.

Algumas conclusões da análise aqui criticadas ancoram-se na idéia de que as oportunidades de investimento eram tão grandes que, mesmo com todas as distorções, a Coréia não tinha como falhar. Essa análise perde pontos importantes ao desconsiderar que o sucesso no desenvolvimento econômico foi muito mais a exceção do que a regra. Esse viés é explicado pela concepção implícita, presente desde Adam Smith, de que "pouco mais é necessário para conduzir uma nação do mais baixo barbarismo até o mais elevado grau de opulência do que paz, impostos razoáveis e uma administração tolerável da justiça; tudo o mais sendo trazido pelo curso natural das coisas"14. Portanto, foge a tais abordagens que existem inúmeros pré-requisitos para que os países beneficiemse das potencialidades do mercado. Boas políticas econômicas contam, mas é necessário muito mais, pelo menos nas fases iniciais do desenvolvimento.

\section{AS INSTITUIÇÕES E OS DIFERENTES MODELOS DE CAPITALISMO}

As instituições importam. Uma vez que os países passam por processos históricos distintos, tendem a ser caracterizados por diferenças na organização da economia e do Estado. Ainda no século XIX, os países que procuraram responder à liderança inglesa moldaram suas instituições de forma distinta. Diferenças profundas marcaram o próprio processo de modernização, sendo que países como Alemanha e Japão responderam aos desafios internacionais por meio de reformas conduzidas pelo próprio Estado (SKOCPOL, 1979). Diferenças marcaram portanto não apenas as características das empresas, do sistema financeiro e dos sistemas educacionais, mas também o papel do Estado e sua forma de interação com os grupos sociais e com a economia.

As instituições explicam, por sua vez, as diferenças nas trajetórias econômicas. Políticas e estratégias econômicas não são simplesmente respostas técnicas a desafios econômicos. Os fatores institucionais, relacionados à organização do Estado, à organização dos grupos sociais e aos mecanismos de interação entre o Estado e a soci-

14 Passagem extraída dos rascunhos de "Riqueza das Nações”, citado por Fonseca (1993, p. 120). 
edade, são centrais para explicar porque países respondem diferentemente a desafios similares. As instituições, ao cristalizarem interesses e mostrarem certa resistência à mudança, são essenciais para entender porque alguns países são bem sucedidos, enquanto outros falham (HALL, 1986).

$\mathrm{O}$ avanço nos estudos institucionais e comparados foi significativo a partir dos anos 1980, consolidando uma ampla literatura batizada de "modelos (ou variedades) de capitalismo". Essa vertente destaca as diferenças institucionais entre os países, enfatizando as diferenças entre um capitalismo liberal, típico de países anglo-saxões, e um capitalismo coordenado, praticado na Alemanha e no Japão. Tratam-se de diferenças a marcar a organização empresarial, o sistema financeiro, o papel do Estado e as relações de trabalho (COATES, 2000; HALL \& SOSKICE, 2001; GUIMARÃES, 2007).

O capitalismo liberal destaca-se por formas de regulação muito centradas em hierarquias e em mercados. Apresenta como características um mercado de trabalho muito flexível, uma grande dependência das empresas em relação ao mercado de capitais, um Estado relativamente pouco intervencionista e poucas formas de colaboração entre as empresas. Esse modelo de capitalismo apresenta, como principal vantagem, sua agilidade e flexibilidade, favorecidas pela baixa regulação e pela grande capacidade dos gerentes tomarem decisões e explorarem novas oportunidades. Apresenta, como principais desvantagens, condições de trabalho precárias e o alto grau de desigualdade.

O capitalismo coordenado, por sua vez, destaca-se pela maior presença de formas de regulação via networks. Na Alemanha, destacamse a força dos sindicatos e suas relações de cooperação com as empresas. Os salários são altos e as firmas enfrentam fortes dificuldades para demitir. Entretanto, a alta qualidade da força de trabalho, favorecida por programas de treinamento e pelo comprometimento mútuo das empresas e dos trabalhadores, garante vantagens comparativas em setores mais sofisticados e grande capacidade de inovação no chão da fábrica. As associações empresariais, por sua vez, favorecem um padrão de cooperação entre as empresas, centrado em práticas conjuntas de treinamento, assistência técnica, desenvolvimento do produto e pesquisa e desenvolvimento. Além disso, as relações próxi- mas entre bancos e empresas garantiram, até o final dos anos 1980, amplo aporte de capital a taxas mais baixas, reduzindo o risco e favorecendo o investimento. Em síntese, esse modelo destacase pela capacidade de conciliar o dinamismo do capitalismo com melhores padrões de igualdade; tem, como principal desafio, a necessidade de tornar-se mais ágil e responder aos desafios de uma economia mais internacionalizada.

Enfim, o capitalismo japonês foi marcado pela constituição de grandes grupos empresarias que desenvolveram práticas de ações cruzadas entre as empresas e entre estas e os bancos. A presença de empresas no mesmo grupo favoreceu práticas conjuntas de inovação e desenvolvimento do produto, enquanto a proximidade com os bancos permitiu grande mobilização de capital a taxas de juros reduzidas. As empresas também desenvolveram relações de cooperação com os fornecedores, reduzindo significativamente os custos de transação e estimulando a inovação ao longo da cadeia produtiva. As relações de trabalho, internas ao grupo e centradas em práticas de emprego vitalício e senioridade, favoreceram o comprometimento do trabalhador, assim como a maior qualificação e a maior autonomia no processo produtivo. Enfim, esse modelo foi marcado pelo forte papel do Estado na coordenação do processo de industrialização, atuando na alocação de recursos financeiros, estimulando o desenvolvimento tecnológico e implementando ações voltadas para o aumento da competitividade (JOHNSON, 1982).

Em síntese, essa literatura aponta para as diferenças institucionais entre os países e para a complementaridade que existe entre as instituições, ajudando a entender as vantagens de cada modelo, assim como os desafios e as dificuldades de transformação. A análise comparativa mostra como a constituição de formas de coordenação via networks, tanto na Alemanha como no Japão, desempenhou importante papel no desenvolvimento desses países e na capacidade de desafiar o modelo norte-americano. Nas últimas décadas, no entanto, a intensificação das forças de mercado em escala mundial vem colocando fortes dificuldades para formas de coordenação alternativas ao mercado, forçando a Alemanha e o Japão a reformular suas instituições. Em importantes aspectos, no entanto, esses países vêm respondendo sem caminhar em direção a um modelo liberal (HALL \& SOSKICE, 2001). 
Essas constatações são muito apropriadas para a interpretação do caso coreano. $O$ sucesso desse país deveu-se a um modelo institucional diferente do anglo-saxão, muito baseado no modelo japonês. Análises que descaracterizam suas particularidades institucionais, interpretando-as à luz de teorias abstratas e dos cânones do modelo liberal anglo-saxão, falham e são incapazes de entender o sucesso do processo de desenvolvimento, assim como a crise. Além disso, essas teorias, ao respaldar projetos de reforma - impostos pela influência política dos Estados Unidos e pelo poder financeiro do FMI -, tenderam a promover direções que não foram as mais adequadas à economia coreana (CHANG, 2006).

\section{O PAPEL DA ORGANIZAÇÃO EMPRESA- RIAL}

O sucesso coreano foi criticamente influenciado pelo tipo de organização empresarial, copiado dos japoneses, que deu ao país, ao contrário de outros países em desenvolvimento, uma burguesia industrial forte, com capacidade de inovação e de competir no mercado internacional. Sem negar que a organização em forma de conglomerado tenha favorecido a sobrevivência de subsidiárias ineficientes, o ponto a destacar-se é que essa estrutura empresarial deu à burguesia coreana uma capacidade de investimentos em Pesquisa e Desenvolvimento $(\mathrm{P} \& D)$ que se fez fundamental para o processo de "destruição criadora" 15 e para a capacidade competitiva alcançada pelo país. Os grupos empresariais, portanto, muito contribuíram para as altas taxas de crescimento econômico, ancoradas em altas taxas de investimento, mas também em fortes aumentos de produtividade, fundamentais para explicar a capacidade de competição nos mercados internacionais e também a significativa elevação dos salários, que acompanharam os ganhos de produtividade. ${ }^{16}$

15 Essa capacidade teria, portanto, compensado amplamente a falta de bons mecanismos de exit (saída), destacados por Joh (2004). Encontramos, nesse ponto, ecos da defesa de Schumpeter (1989) dos oligopólios, efetuada no capítulo 8 do seu Capitalismo, Socialismo e Democracia.

16 Easterly (2004,p. 92-93) cita uma série de estudos que, enfatizando a interdependência entre investimento e progresso técnico, sugerem que a contribuição da produtividade para o crescimento teria sido muito maior do que o sugerido por alguns autores. Alguns estudos chegam a sugerir que $91 \%$ do crescimento do produto por trabalhador
A estrutura empresarial permitiu, assim, a consolidação de uma estrutura industrial sólida, que prescindiu de uma forte presença do capital estrangeiro e conservou uma maior autonomia em decisões centrais para o funcionamento da economia. Por trás desse resultado encontra-se a ação decisiva do Estado no controle ao capital estrangeiro e no auxilio às empresas na negociação de contratos de importação de tecnologia, de forma a garantir boas condições de absorção tecnológica ${ }^{17}$. Por trás de todo esse processo, encontra-se a força do Estado coreano para superar constrangimentos internos e externos à adoção de uma política nacional mais autônoma ${ }^{18}$. Isso permitiu reverter políticas que, nos anos 1950, aproximavam o modelo coreano de muitas características dos países latino-americanos ${ }^{19}$.

na Coréia, em Taiwan, em Cingapura e em Hong Kong deveu-se ao progresso tecnológico, negando enfaticamente a tese de Krugman dos "tigres de papel".

17 Essas condições permitiram à Coréia escapar, ao contrário de vários outros países, da etapa do desenvolvimento dependente (CARDOSO \& FALETTO, 1970). Nessa etapa, decisões críticas para o funcionamento da economia são tomadas no exterior, ao mesmo tempo em que os interesses da burguesia nacional interligam-se ao núcleo dinâmico (e internacional) da economia. Reduz-se, portanto, a autonomia do Estado, assim como sua capacidade de promover políticas destinadas ao desenvolvimento tecnológico. Como mostram Cardoso e Faletto (idem, p. 129), escapar a essa situação de dependência era uma tarefa muito difícil, a exigir intensa mobilização dos recursos existentes no interior dos países. Segundo esses autores, era uma possibilidade que se encontrava, nos anos 1960, aberta apenas a países como Rússia, China e Japão. Em retrospecto, a Coréia do Sul pode também ser incluída nesse grupo.

18 Como mostram Cardoso e Faletto (idem), as dificuldades de desenvolvimento explicam-se também pela estrutura de forças sociais que marca cada país, dado que os grupos mais influentes tendem a constranger a adoção de certas políticas. No caso latino-americano, esses constrangimentos, traduzindo em polarização entre as classes sociais e também em dificuldades no balanço de pagamentos, empurrou os países a aumentar a dependência do capital estrangeiro.

19 Esse é um ponto central para entender por que o modelo coreano foi marcado por menos distorções que em outros países. Não se trata apenas de saber quais as melhores políticas, mas de ter capacidade de aplicá-las. Nos anos 1960, a pressão norte-americana exigiu uma política cambial favorável às exportações e uma política menos permissiva em relação à inflação. Mas a capacidade de adotá-las foi fortemente influenciada pela força do Estado em relação aos grupos de interesse (HAGGARD, 1990). 
Em síntese, a forma de organização empresarial cumpriu importante papel para o sucesso do modelo. As firmas coreanas não eram ineficientes, sendo o catch up (convergência) em vários setores e a capacidade de competição internacional evidências incontestes de sua capacidade e eficiência. Esse ponto é reforçado por Chang, Park e Yoo (1998), que mostram que a baixa lucratividade das empresas esteve em grande parte relacionada ao alto pagamento de juros. Quando se considera a lucratividade antes do pagamento de juros, as firmas coreanas não se encontram abaixo do padrão internacional ${ }^{20}$. Isso, portanto, reforça a evidência de que a baixa lucratividade está também relacionada a uma estratégia que visava maximizar o controle de fatias de mercado, estratégia apenas possível devido à existência de um capital mais paciente, fruto da relação desenvolvida entre bancos e empresas.

\section{O DEVELOPMENTAL STATE EM QUES- TÃO}

Outro pilar do desenvolvimento coreano, usualmente desconsiderado em função do viés da análise convencional, foi o papel do Estado. Como bem mostra Peter Evans (2004), o Estado não pode, em nenhum país, ser descrito como um conjunto de agentes que maximizam interesses individuais. Essa caracterização está mais próxima dos Estados pré-modernos, sendo uma característica distintiva do Estado moderno a constituição de uma burocracia que possui um ethos diferente e cuja ação é essencial para o funcionamento do próprio mecanismo de mercado ${ }^{21}$. A constituição de uma burocracia com tais características é um dos grandes desafios para o desenvolvimento, sendo que muitos países falham pela incapacidade de construí-la. No caso do leste asiático, no entanto, essa burocracia atingiu um grau

20 Segundo Chang, Park e Yoo (1998, p. 742), a lucratividade das firmas coreanas no período de 1973 a 1996 , após o pagamento de juros, teria sido de $2,8 \%$, contra 4,3\% no Japão (1955-73), 5,1\% em Taiwan (1995) e $7,9 \%$ nos Estados Unidos (1995). Mas quando se considera a lucratividade antes do pagamento de juros, a Coréia obteve 7,4\%, contra 7,7\% para os Estados Unidos, 7,3\% para Taiwan e 7,2\% para o Japão (nesse último país, para o período 1961-73; para os demais países, os anos são os mesmos da comparação anterior).

21 Em outras palavras, como bem lembra Chang (2006, p. 50), o mercado é também uma instituição, cujo bom funcionamento depende igualmente de bons fundamentos. de coesão, insulamento e capacitação bem acima da média (JOHNSON, 1982; WORLD BANK, 1993; EVANS, 2004). Permitiu-se, dessa forma, a consolidação de Developmental States, que vieram a ter papel central na coordenação do processo de desenvolvimento.

Esse é um ponto muito bem destacado pelo estudo do Banco Mundial, The East Asian Miracle, publicado em 1993. O estudo, que também endossa a importância dos fundamentos macroeconômicos, do bom sistema educacional e dos estímulos à taxa de poupança ${ }^{22}$, dá ênfase especial aos elementos institucionais responsáveis pelo desempenho do Estado em países do leste asiático. Entre as formas de intervenção direta do Estado na economia, o estudo destaca a preservação de baixas (embora positivas) taxas de juros, a direção de crédito subsidiário para setores da indústria, a proteção tarifária, o auxílio a indústrias em declínio, os investimentos e incentivos à Pesquisa e Desenvolvimento e a criação de agências para a promoção de exportações. Deve-se destacar nesse conjunto de medidas a adoção de uma política industrial agressiva, com a concessão de licenças exclusivas e o acesso generoso ao crédito para as empresas que se dispusessem a investir nos setores considerados estratégicos.

O ponto do estudo não é afirmar que essas políticas geram, necessariamente, bons resultados, dado que existem inúmeros exemplos de ocorrência do contrário, e sim destacar como a qualidade institucional da burocracia e os mecanismos de coordenação entre o setor público e o setor privado foram capazes de gerar os resultados positivos. A qualidade da burocracia foi influenciada por raízes culturais e históricas que valorizavam o treinamento e a preparação cuidadosa de um grupo para governar o país. Além disso, foi favorecida pelas regras de recrutamento e treinamento: a burocracia era recrutada das melhores escolas e apenas uma proporção muito reduzida era aprovada nos exames. Os salários eram altos e competitivos com o setor privado. Tudo isso,

22 Segundo esse estudo, um bom sistema educacional foi muito importante para aumentar a oferta de capital humano e para disseminar os frutos do crescimento. Além disso, o governo desempenhou bem a função de provedor de bens públicos, evitou distorções nos preços agrícolas e nos preços dos bens de capital e garantiu taxas de inflação relativamente baixas e um câmbio favorável às exportações (WORLD BANK, 1993). 
aliado a práticas que favoreciam a coesão da corporação, contribuiu para uma classe insulada e preparada para a intervenção. Como destaca o estudo, "effective implementation of contests depended on two sets of factors almost unique to the northern HPAES (High Performing Asian Economies). The first is the competence, insulation, and relative lack of corruptibility of the public administrations in Japan and Korea" 23 (WORLD BANK, 1993, p. 102).

Um ponto central para o sucesso da intervenção foi o permanente processo de monitoramento que, centrado na determinação de metas para exportações e eficiência, evitava a acomodação e garantia bons resultados. As empresas incapazes de atingir essas metas eram empurradas para a falência. Em setores em que a lucratividade era muito alta, o governo exigia o direcionamento de recursos para atividades com altas externalidades positivas $^{24}$. Ao conectar os incentivos a bons resultados em termos de competitividade, a intervenção influenciava positivamente a alocação do crédito: "there is some evidence that in Japan, Korea, and Taiwan, China, governments allocated credit to activities with high social returns, especially to exports. If this was the case, there may have been benefits from mild financial repression and government guided allocation; evidence from Japan support the view that access to government credit increased investment" 25 (idem, p. 17).

Um ponto central para o sucesso da intervenção foi a criação de canais e órgãos que favoreci-

23 “A implementação bem sucedida de certas políticas dependeu da combinação de dois tipos de requisitos encontrados de forma praticamente única no grupo de países de alto desempenho econômico do nordeste da Ásia. O primeiro é o alto grau de competência e coesão da administração pública no Japão e na Coréia, acompanhados de um baixíssimo grau de corrupção" (tradução nossa).

24 Ou seja, para setores cuja contribuição para o restante da economia seja elevada.

25 "Há alguma evidência de que no Japão, na Coréia e em Taiwan (China), a intervenção governamental contribuiu para que o crédito fosse direcionado para atividades com algo retorno social, especialmente para as exportações. Se esse foi de fato o caso, pode-se concluir que as práticas de controle financeiro e de alocação do crédito pelo governo tiveram resultados positivos. Evidências do caso japonês dão suporte à visão de que o acesso ao crédito governamental contribuiu para aumentar o investimento" (tradução nossa). am a troca de informações entre o setor público e o privado. São muitos os exemplos de conselhos que proviam a burocracia com informações para melhor desenhar e implementar as políticas. Os conselhos eram marcados pela ampla participação dos líderes empresariais, de forma a determinar tanto direções gerais para a indústria como metas específicas para os setores. Tratava-se, pois, de órgãos abrangentes (encompassing, na terminologia de Mancur Olson, 1982), que impediam a captura das políticas por grupos de interesses, algo, portanto, muito diferente dos lobbies e rent seeking ("captura de renda") destacados pelas teorias da Escolha Pública. Em síntese, os conselhos desempenharam papel central para complementar as informações do mercado, de forma a garantir reformas rápidas e precisas a mudanças na situação da economia: "in institutional development, as in economic policymaking, East Asian government have changed with changing circumstances"26 (WORLD BANK, 2003, p. $15)^{27}$.

Em síntese, esses fatores ajudam a explicar uma intervenção que, em regra, foi positiva, voltada para complementar o mercado, para suprir suas falhas e para estimular uma industrialização que, retardatária, precisava preparar-se para enfrentar a competição estrangeira. A qualidade institucional da burocracia e seus mecanismos de conexão com o setor privado explica uma política muito intervencionista, mas que, ao mesmo tempo, preservou bons fundamentos macroeconômicos, evitando maiores distorções ${ }^{28}$.

26 "no desenvolvimento institucional, assim como na formulação da política econômica, os governos do leste da Ásia adaptaram-se às circunstâncias cambiantes" (tradução nossa).

27 Segundo o estudo, a forma de coordenação na Coréia era menos institucionalizada que no Japão. Entretanto, o governo fazia questão de ouvir os empresários e obter as informações necessárias para a adoção das políticas. Um bom exemplo eram as reuniões para a promoção de exportações que, contando inclusive com a participação dos ministros e do Presidente, fornecia informações sobre tecnologia, mercados e impactos da regulação sobre os setores produtivos (WORLD BANK, 1993, p. 183).

28 Ocorreram também dificuldades. Um bom exemplo é o programa de incentivo à indústria química e pesada na Coréia nos anos 1970. Apesar do êxito de fomentar a capacidade industrial, o processo foi marcado por forte acumulação de excesso de capacidade, que explica a desaceleração econômica que se seguiu. Mas a despeito de exemplos como 
Apesar de reconhecer pontos positivos na alocação do crédito, o estudo do Banco Mundial é bem mais cauteloso ao considerar o impacto do programa de intervenção na distribuição setorial da indústria e na criação de vantagens comparativas. $\mathrm{O}$ argumento é que a indústria avançou a partir das vantagens comparativas e que a política industrial, ao exigir bom desempenho e competitividade, acabou reforçando os sinais do mercado e recompensando os setores que tinham potencial para se desenvolver (WORLD BANK, 1993, p. 21-22). Essa conclusão, no entanto, torna o argumento tautológico. Subentende-se que o sucesso ocorreria de qualquer forma, mas não traz nenhum argumento para sustentar esse ponto. A teoria das vantagens comparativas é muito útil para explicar, por exemplo, por que países sem um mínimo de capacitações sociais irão inevitavelmente falhar se adotarem políticas industriais muito ambiciosas. No entanto, torna-se um argumento menos importante para entender como alguns países com certo potencial conseguem, depois de dificuldades iniciais, avançar no processo de produção em certos setores estratégicos.

Peter Evans (2004, p. 135) destaca que, se aceitassem a versão tradicional da teoria das vantagens comparativas, os países de industrialização retardatária ficariam restritos a atividades industriais padronizadas, com destaque para linhas de montagens em setores em declínio. $\mathrm{O}$ autor empreende um cuidadoso e bem fundamentado estudo dos fatores que explicam por que a intervenção do Estado foi bem sucedida em alguns países, quando a regra é o fracasso ou a obtenção de resultados bem inferiores. Sua contribuição para o argumento em questão fica mais bem compreendida por meio de alguns exemplos.

Uma ótima ilustração sobre o potencial produtivo da intervenção estatal foi a política para o desenvolvimento da indústria de computadores no Japão. Nos anos 1960, o governo adotou um rígido controle das licenças de importação, apesar dos protestos dos usuários. Usou esse controle como instrumento de barganha para determinar como seria o acesso da principal multinacional, a IBM, ao mercado japonês. Negociou um contrato de risco para o licenciamento de tecnologia, esten-

esse, a ação do Developmental State foi muito mais favorável do que negativa, sendo central para os bons resultados do modelo de desenvolvimento. dendo o direito de patente a quinze firmas nacionais, que competiam entre si. Ao mesmo tempo, orquestrou a criação de uma firma de propriedade compartilhada pelos produtores e administrada pelo influente Ministério da Indústria e do Comercio Exterior (MITI). Essa firma, abastecida com fundos a juros muito baixos, comprava os computadores dos produtores nacionais e alugava-os aos usuários - em grande parte agências públicas. Nesse ínterim, provia suporte e exercia o monitoramento, de forma a garantir a eficiência (idem, p. 140-142).

Assim, devido à coordenação e ao suporte do governo - que gerenciava um cartel e, simultaneamente, exigia a competição entre seus membros -, um negócio muito arriscado tornou-se atrativo, consolidando a capacidade local de produção. Um ponto central do argumento é que nenhuma dessas ações era por si só decisiva. Mas essas foram acumulando-se e complementando-se, contribuindo para o domínio de um setor de grande potencialidade, estratégico para a inserção da indústria japonesa em outras atividades. Embora o Japão tivesse mão-de-obra qualificada e capacidade empresarial - requisitos importantes para o sucesso da empreitada -, ficaria, na ausência de coordenação estatal, possivelmente sem o controle tecnológico de uma indústria, naquele momento, de grande potencial.

Outro ótimo exemplo é fornecido pela política de informática na Coréia do Sul. Ao contrário do ocorrido em outros países em desenvolvimento, uma política nacional de informática contava com forte apoio dentro do aparato estatal, incluindo o Ministério das Comunicações, particularmente interessado no provimento, a baixos custos, de equipamentos de excelência e qualidade. A menor divisão de seu aparato ajuda a explicar uma política estatal mais coesa, requisito para os bons resultados obtidos ${ }^{29}$. Além disso, as agências responsáveis pela política contavam com técnicos qualificados e com amplo acesso a recursos financeiros (idem, p. 151-153).

Um papel essencial, no entanto, foi desempenhado pela organização do capital, devido ao fato de o país contar com grupos empresariais nacio-

29 No caso brasileiro, por exemplo, o Ministério das Comunicações aliou-se com importadores e usuários, reforçando a oposição à Política de Informática (EVANS, 2004, p. 148-151). 
nais com porte e capacidade para investir em Pesquisa e Desenvolvimento. Esses grupos, que detinham já sólida base em eletrônica, tinham todo o interesse em colaborar com o governo para dominar o processo produtivo no setor de informática. Apoiaram, portanto, a política do governo, ao invés de oporem-se a ela, como seria provavelmente o caso de uma estrutura empresarial muito dependente do capital estrangeiro ${ }^{30}$.

O sucesso da intervenção deveu-se, vale mais uma vez ressaltar, a políticas que complementaram a ação do setor privado, em vez de tentar substituí-la. O governo empenhou-se na oferta de funções de suporte, ao mesmo tempo em que contribuía para a redução do risco dos investimentos. Uma política de compras das agências estatais garantiu a demanda inicial aos produtores. O governo investiu fortemente em Pesquisa \& Desenvolvimento, ao mesmo tempo em que obteve sucesso em convencer o setor privado também a fazê-lo ${ }^{31}$. Simultaneamente, o governo exercia forte monitoramento para garantir o aumento da eficiência e da competitividade. Como bem sintetiza Evans (idem), tratava-se da tarefa de pastoreio, criando uma estufa, arbitrando as relações com as firmas estrangeiras e gerando condições para as empresas nacionais avançarem tecnologicamente.

Evans (idem) aponta outros exemplos muito persuasivos da importância do Estado para o sucesso da industrialização na Coréia. No início da industrialização, uma empresa estatal obteve grande sucesso na produção siderúrgica, gerando capacidade de produção de um insumo estratégico a custos os mais baixos do mundo. Ao estimular a formação de grandes grupos empresariais, o Estado coreano criou também as bases organizacionais para o sucesso de várias indústrias, incluindo a automobilística, um dos exemplos de maior sucesso entre países em desenvolvimento.

30 No Brasil, a Política de Informática entrou em conflito com fatores inerentes ao desenvolvimento dependente. Além da forte presença de multinacionais, havia muitos setores que dependiam da importação de tecnologia, além de outros que desejavam apenas importar a baixos custos. Esses setores possuíam, devido aos anéis burocráticos, bons canais de acesso ao aparato estatal.

31 Aqui há novamente forte diferença com o Brasil, em que o alto grau de incerteza e a insegurança do arranjo desestimularam o setor privado a investir em tecnologia.
Em síntese, o estudo de Evans e o do Banco Mundial complementam-se ao destacar as fontes institucionais de sucesso da intervenção estatal no leste asiático. A existência de uma burocracia bem preparada e autônoma, que possuía canais de interação com a sociedade, permitiu o desenho, a implementação e o acompanhamento das políticas de desenvolvimento em níveis satisfatórios. Ao facilitar a coordenação, encorajar certos investimentos e monitorar seu desempenho, o Estado contribuiu para o êxito do modelo industrial nesses países.

\section{CONCLUSÕES}

A principal contribuição do presente artigo consiste em apontar uma inconsistência central de análises mais ortodoxas e liberais, que, nos últimos anos, vem recuperando espaço no debate sobre economia política comparada. Implícita na interpretação aqui criticada está a visão de que existe um tipo mais eficiente de organização econômica e de que alternativas a esse tipo de arranjo tendem, inexoravelmente, ao desencadeamento de crises e dificuldades.

Em 1993, o trabalho do Banco Mundial representou um forte golpe contra o argumento liberal mais extremado, pois mostrava que havia algo diferente na organização institucional das economias do leste asiático e atribuía a traços dessa organização a responsabilidade pelo sucesso dos respectivos modelos de desenvolvimento. O argumento sinalizava, portanto, em direção contrária à contra-revolução liberal que, desde os anos 1970, fortalecia-se no debate sobre o desenvolvimento, atribuindo às falhas do Estado a principal razão para o fracasso das estratégias adotadas pelos países em desenvolvimento (MEIER, 2000)

A crise asiática, somada às dificuldades do Japão e da Alemanha nos anos 1990, deu aos liberais a possibilidade de contra-atacarem, voltando a atribuir à intervenção do Estado e às formas de coordenação alternativas ao mercado as principais causas das dificuldades econômicas desses países. Segundo esse contra-argumento, os últimos eventos teriam restabelecido a verdade, escondida durante a fase de crescimento extensivo e em um contexto institucional que permitia a certas economias insularem-se das forças de mercado.

Observando em detalhes a experiência coreana, é necessário destacar que o argumento 
liberal tem razão ao apontar a necessidade de uma boa estrutura de regras formais para o bom funcionamento de uma economia de mercado. Ao indicar as falhas de regulação do sistema financeiro e a pouca transparência das práticas corporativas, o argumento indica fontes de fragilidades que são fundamentais para entender as causas da crise de 1997, assim como sua magnitude. Essa contribuição, no entanto, não autoriza atribuir as dificuldades financeiras à ineficiência da estrutura empresarial ou à intervenção do Estado na economia. E tampouco justifica desqualificar a relevância de certas práticas e instituições para o inconteste sucesso obtido pela economia coreana.

A crise não pode, portanto, ser deduzida das pretensas fontes de ineficiência do modelo coreano, por mais que algumas características sejam importantes para seu entendimento. Está muito mais relacionada a um processo mal conduzido de desregulamentação financeira, fruto da pressão internacional e da pressão interna dos chaebols, ávidos por novas oportunidades de valorização de seu capital. Esse processo levou a um forte endividamento de curto prazo, aumentando em muito as dificuldades de um já frágil sistema financeiro. O endividamento, por sua vez, favoreceu uma explosão ("boom") de investimento interno que, provocando excesso de capacidade, acelerou a queda de lucratividade da economia (CHANG, PARK \& YOO, 1998).

Esse raciocínio leva a um segundo ponto: o impacto do enfraquecimento da coordenação estatal na economia. No período anterior à liberalização, as autoridades orquestravam, com mão de ferro, a distribuição do investimento pela economia, procurando evitar a acumulação de excesso de capacidade em alguns setores. Nos anos 1980 e 1990, no entanto, a política industrial passa a enfrentar forte oposição, resultado da disseminação de idéias liberais, das pressões internacionais e do fortalecimento dos chaebols. Assim, em 1993, o antes influente Economic Planning Board foi fundido com o Ministério da Fazenda, em prejuízo da capacidade de planejamento (CHANG, PARK E YOO, 1998, p. 739). Apesar de medidas disfarçadas para modernizar alguns setores, a política industrial entra em declínio, o que ajuda a explicar a acumulação de capacidade ociosa em certos setores.
O ponto a destacar-se é que existia um arranjo de coordenação prévio, que propiciava um controle sobre o fluxo de capitais, ao mesmo tempo em que mantinha sob controle a ação dos grandes grupos empresariais, evitando que sua alta capacidade de alavancagem financeira gerasse excesso de capacidade em certos setores. Com essa estrutura de regulação, conseguia-se evitar que, apesar da falta de boas regras de governança corporativa e de regulação financeira, os desequilíbrios e dificuldades acumulassem-se (WOO-CUMINGS, 1999; CHANG, PARK \& YOO, 1998). O ocaso dessa estrutura de coordenação, no entanto, ocorreu antes que se fortalecessem os mecanismos de regulação mais próprios a uma economia de mercado. O resultado foi o endividamento excessivo e de curto prazo em moeda estrangeira, agravando a fragilidade financeira e a acumulação de excesso de capacidade em setores-chaves.

Um equívoco grave do argumento liberal está na caracterização do Estado coreano como fonte de rent seeking e corrupção. Como argumentado acima, a ação da burocracia era rigorosa, pautada em uma racionalidade weberiana que valorizava a disciplina e a meritocracia. As empresas eram fortemente monitoradas e aquelas que não alcançavam padrões de eficiência eram punidas. Há também necessidade de cautela ao se falar de moral hazard $^{32}$ : quando as firmas eram assistidas, os burocratas exigiam uma reestruturação profunda ou a incorporação por outras empresas. O gerenciamento era punido e mudanças corretivas eram impostas (CHANG, PARK \& YOO, 1998, p. 743).

Nos anos 1990, é possível identificar o crescimento das dificuldades, provocado pelo fortalecimento dos chaebols e pelo enfraquecimento da burocracia. Embora a corrupção tenha sempre existido, é factível supor que tenha se elevado significativamente como resultado do menor insulamento da burocracia e da maior autonomia dos políticos, então muito dependentes dos chaebols para financiamento e apoio político (WOO-CUMMINGS, 1999). Essa nova situação explica os escândalos de corrupção que negativamente contribuíram para a perda de credibilidade

\footnotetext{
32 "Risco moral".
} 
da economia coreana, gerando desconfiança por parte dos investidores estrangeiros. Esses escândalos, no entanto, nada tiveram a ver com a organização das empresas ou com o padrão de intervenção estatal que caracterizou o modelo desenvolvimentista.

Na mesma linha, não faz sentido atribuir a crise ao comportamento irresponsável das empresas. As firmas eram eficientes e competitivas, estando a lucratividade mais baixa relacionada ao alto pagamento de juros, explicado pelas relações próximas com os bancos e pela adoção de estratégias voltadas para o controle de parcelas do mercado. Apesar da preservação de subsidiárias ineficientes, a estrutura dos grandes grupos empresariais favoreceu também grandes investimentos em inovação e a acumulação de vantagens de escopo, importantes para a conquista da liderança mundial em vários segmentos da indústria. Nas vésperas da crise, os chaebols concentravam seus investimentos nos setores tradicionais e competitivos, e não em investimentos especulativos, como seria o caso típico de uma economia com "risco moral" (CHANG, PARK \& YOO, 1998, p. 743-744).

O problema mais sério era o alto grau de endividamento de alguns chaebols, destacando o endividamento de curto prazo em capital estrangeiro e o grande endividamento com instituições financeiras não bancárias, cuja estrutura de regulação era ainda mais precária. É necessário insistir nas dificuldades relacionadas à governança corporativa e, principalmente, à falta de transparência na divulgação de informações. Essas dificuldades, no entanto, estão sendo equacionadas, não implicando, portanto, a necessidade de reforma empresarial na direção de um padrão anglo-saxão, o que tenderia, como em parte vem ocorrendo, a comprometer a capacidade de inovação e de competição dos grupos coreanos (LEE et alii, 2005).

Em suma, a crise não está ligada às formas de coordenação do capitalismo coreano; pelo contrário, essas formas desempenharam papel relevante para o êxito da industrialização. A crise explica-se por um processo mal conduzido de desregulamentação financeira e pelo abandono das formas tradicionais de coordenação antes que uma estrutura substituta estivesse estabelecida. Apesar das mudanças que se seguiram à crise, devese destacar a preservação de traços peculiares ao capitalismo coreano, incluindo traços da organi- zação empresarial e o padrão mais intervencionista de ação estatal ${ }^{33}$. Este desempenhou um papel importante no processo de reformas, conservando características típicas do tradicional Developmental State que contribuíram para a velocidade e para o êxito do processo (WEISS, 2003).

Em alguns aspectos, mudanças corretivas tornaram a economia mais sólida. Em outros, no entanto, há sinais de efeitos negativos sobre a capacidade de investimento e de inovação. A adoção de regras internacionais rígidas, incluindo regras de adequação de capital (minimum capital adequacy standard) para as instituições bancárias, acarretou em forte restrição de liquidez. Instituições bancárias com potencial de recuperação foram fechadas, enquanto a forma rígida de aplicação do critério impediu o socorro a empresas viáveis que, embora em dificuldades financeiras, apresentavam potencial de recuperação (CHANG, 2006, p. 298-299).

A estrutura dos chaebols foi também modificada, proibindo operações intra-grupo que até então eram usadas para dar suporte a estratégias de longo prazo. Os chaebols, assim como outras empresas, sofreram significativamente com a maior restrição no acesso ao crédito. Como conseqüência, o período posterior às reformas, apesar de ser de forte recuperação, foi caracterizado por menor crescimento das vendas, menor crescimento econômico e menor absorção de empregos do que no período anterior à crise. Houve também queda significativa nas taxas de investimento, que de um patamar de $37 \%$ do PIB no período $1990-97$ caíram para $27 \%$ no período 1998-2001 (CHANG, 2006).

Os resultados apontam portanto para dificuldades advindas da introdução de reformas e regras muito centradas em critérios financeiros e muito influenciadas pelos padrões do capitalismo liberal. Os resultados teriam sido melhores se, junto com as medidas voltadas para aumentar a transparência e melhorar a regulação, fossem preservados os traços institucionais que tanto favoreceram o desenvolvimento anterior. Embora o grau de endividamento e a lucratividade de curto prazo sejam indicadores a serem observados, estes não podem ser encarados como um fim em si mesmo.

33 Embora o padrão de intervenção seja hoje bem diferente do passado, mais centrado em coordenar os atores e em estimular investimentos em Pesquisa e Desenvolvimento. 
Alexandre Queiroz Guimarães (alexandre.queiroz@fjp.mg.gov.br) é Doutor em Politics pela Sheffield University, Professor de Economia na Pontifícia Universidade Católica de Minas Gerais (PUC-MG) e Professor de Administração Pública na Escola de Governo da Fundação João Pinheiro.

\section{REFERÊNCIAS BIBLIOGRÁFICAS}

CARDOSO, F. H. \& FALETTO, E. 1970. Dependência e Desenvolvimento na América Latina: ensaio de interpretação sociológica. $7^{\mathrm{a}} \mathrm{ed}$. Rio de Janeiro : J. Zahar.

CHANG, H-J.; PARK, H. J. \& YOO, C. G. 1998. Interpreting the Korean Crisis : Financial Liberalisation, Industrial Policy and Corporate Governance. Cambridge Journal of Economics, Cambridge, v. 22, n. 6, p. 735746.

CHANG, H-J. 2006. The East Asian Development Experience : the Miracle, the Crisis and the Future. Penang : Third World Network.

CHOI, Y-K. \& KIM, D. I. 2004. Changes in the Labor Markets and Industrial Relations. In : CHUNG, D-K. \& EICHENGREEN, B. The Korean Economy Beyond the Crisis. Cheltenham-Northampton : Edward Elgar.

CHUNG, U-C. 2004. The Korean Economy Before and After the Crisis. In : CHUNG, D-K. \& EICHENGREEN, B. (orgs.). The Korean Economy Beyond the Crisis. CheltenhamNorthampton : Edward Elgar.

COATES, D. 2000. Models of Capitalism : Growth and Stagnation in the Modern Era. Oxford : Polity.

EASTERLY, W. 2004. O Espetáculo do Crescimento : aventuras e desventuras dos economistas na incessante busca pela prosperidade nos trópicos. Rio de Janeiro : Ediouro.

EICHENGREEN, B. \& CHUNG, D-K. 2004. Introduction. In : CHUNG, D-K. \& EICHENGREEN, B. (orgs.). The Korean Economy Beyond the Crisis. CheltenhamNorthampton : Edward Elgar.

EVANS, P. 2004. Autonomia e Parceria : Estados e transformação industrial. Rio de Janeiro : UFRJ.

FONSECA, E. G. 1993. Vícios Privados, Beneficios Públicos? : a ética na Riqueza das Nações. São Paulo : Cia. das Letras.
GUIMARÃES, A. 2007. Modelos de Capitalismo e Economia Política Comparada : instituições, performance e as respostas alemã e japonesa aos desafios recentes. Dados, Rio de Janeiro, v. 20 , n. 1, p. 159-188. Disponível em : http:/ /www.scielo.br/pdf/dados/v 50 n $1 /$ a06v50n1.pdf Acesso em : 5.ago.2009.

HAGGARD, S. 1990. Pathways from the Periphery: the Politics of Growth in the Newly Industrialising Countries. New York : Cornell University.

HALL, P. \& SOSKICE, D. 2001. An Introduction to Varieties of Capitalism. In : HALL, P. \& SOSKICE, D. Varieties of Capitalism : the Institutional Foundations of Comparative Advantage. Oxford : Oxford University.

HALL, P. 1986. Governing the Economy : the Politics of State Intervention in Britain and France. Cambridge : Polity.

HAMN, J-H. 2004. Financial Restructuring. In : CHUNG, D-K. \& EICHENGREEN, B. (orgs.). The Korean Economy Beyond the Crisis. Cheltenham-Northampton : Edward Elgar.

JOH, S. W. 2004. Corporate Restructuring. In : CHUNG, D-K. \& EICHENGREEN, B. (orgs.). The Korean Economy Beyond the Crisis. Cheltenham-Northampton : Edward Elgar.

JOHNSON, C. 1982. MITI and the Japanese Miracle : the Growth of Industrial Policy, 1925-1975. Stanford : Stanford University.

JUN, J. 2004. The Fiscal Policy Response to the Crisis. In : CHUNG, D-K. \& EICHENGREEN, B. (orgs.). The Korean Economy Beyond the Crisis. Cheltenham-Northampton : Edward Elgar.

KOHLI, A. 2004. State Directed Development : Political Power and Industrialization in the Global Periphery. New York : Cambridge University.

LEE, J-W. 2004. Social Impacts of the Crisis. In : CHUNG, D-K. \& EICHENGREEN, B. (orgs.). The Korean Economy Beyond the 
Crisis. Cheltenham-Northampton : Edward Elgar.

LEE, K.; KIM, B-K.; LEE, C. \& YEE, J. 2005. Visible Success and Invisible Failure in PostCrisis Reform in the Republic of Korea : Interplay of Global Standards, Agents, and Local Specificity. World Bank Policy Research Working Paper, Washington, n. 3651, Jun. Disponível em : http://wwww d s.worldbank.org/s e rvlet/ WDSContentServer/WDSP/IB/2005/06/16/ 000016406_20050616112817/Rendered/PDF/ wps3651.pdf Acesso em : 6.ago.2009.

MEIER, G. 2000. The Old Generation of Development Economists and the New. In : MEIER, G. \& STIGLITZ, J. Frontiers of Development Economics : the Future in Perspective. Washington-New York : The World Bank-Oxford University.

OLSON, M. 1982. The Rise and Decline of Nations : Economic Growth, Stagflation and Social Rigidities. New Haven : Yale University.

PARK, W-A. \& CHOI, G. 2004. What Caused

the Crisis? A Post Mortem. In : CHUNG, D-K. \& EICHENGREEN, B. (orgs.). The Korean Economy Beyond the Crisis. CheltenhamNorthampton : Edward Elgar.

SCHUMPETER, J. 1989. Capitalismo Socialismo e Democracia. Rio de Janeiro : J. Zahar.

SILVEIRA, A. M. 1991. A indeterminação de Senior. Revista de Economia Política, São Paulo, v. 11, n. 4, p. 70-88, out.-dez. Disponível em : http://www.rep.org.br/pdf/44-5.pdf Acesso em : 6.ago.2009.

SKOCPOL, T. 1979. States \& Social Revolutions : a Comparative Analyses of France, Russia \& China. Cambridge : Cambridge University.

WEISS, L. 2003. States in the Global Economy: Bringing Domestic Institutions Back In. Cambridge : Cambridge University.

WOO-CUMINGS, M. 1999. The State, Democracy, and the Reform of the Corporate Sector in Korea. In : PEMPEL, T. J. The Politics of the Asian Economic Crisis. IthacaLondon : Cornell University.

\section{OUTRAS FONTES}

PENN WORLD TABLE. 2009. Sítio do banco de dados Penn World Table. Center for International Comparisons at the University of Pennsylvania. Disponível em : http:// pwt.econ.upenn.edu/php_site/pwt_index.php Acesso em: 10.ago.2009.
WORLD BANK. 1993. The East Asian Miracle: economic growth and public policy. New York: Oxford University. 
STATE, INSTITUTIONS AND DEVELOPMENT: THE KOREAN MODEL AND THE INTERPRETATION OF THE ASIAN CRISIS

\section{Alexandre Queiroz Guimarães}

The present article is part of a theoretical line that researches the relationship between institutions, the State and economic performance. Its central object is the study of Developmental States, that is, interventionist states that performed a central role in the development strategies of certain countries. In spite of the numerous historical analyses that have been carried out regarding these experiences, the theme is considered controversial and many economists are reluctant in accepting that such states made any positive contribution. The article therefore deals with a theme that is very dear to economic science from the upstart, the relationship between State and market and its impact on the "wealth of nations". It attempts to contribute to this issue through a critique of more abstract analyses geared toward interpretation of the Asian model and the 1997 crisis. Identifying a methodological flaw in these analyses, we argue that the crisis cannot be deduced from possible institutional weaknesses in the South Korean model. Institutional characteristics, including the developmental State and large entrepreneurial groups, were the central variables used to explain South Korea's major success in the decades that followed 1960. In this regard, the difficulties of the 1990s should be interpreted as the result of a hurried process of economic liberalization and deregulation, implemented before a new regulatory structure to substitute earlier forms of regulation could be established. In refusing certain interpretations of the crisis, this article emphasizes the importance of recognizing the institutional specificities of different countries and the existence of different types of capitalism. The South Korean case, just as the Japanese one, reveals a model of capitalism in which the Developmental State played an extremely active role, constituting a fundamental variable for explaining the major success that these countries' development strategies were able to achieve.

Keywords: South Korea, Developmental State; models of capitalism; Asian crisis; institutions, development. 


\section{ÉTAT, INSTITUTIONS ET DÉVELOPPEMENT : LE MODÈLE CORÉEN ET L'INTERPRÉTATION DE LA CRISE ASIATIQUE}

\section{Alexandre Queiroz Guimarães}

Cet article fait partie d'une ligne d'étude centrée sur l'investigation des relations entre les institutions, l'État et la performance économique. Il a comme objet principal l'étude des États développementistes (Developmental States), c'est-à-dire les états interventionnistes qui ont joué un rôle important dans les stratégies de développement de certains pays. Malgré plusieurs analyses historiques sur ces expériences, le thème est considéré comme conflictuel et bien des économistes résistent à accepter que ces états ont positivement contribué. L'article porte, donc, sur un thème cher à la science économique depuis ses origines : la relation entre l'État et le marché et ses conséquences sur « la richesse des nations ». Il envisage aussi de contribuer à cette thématique à travers une critique des analyses assez abstraites consacrées à l'interprétation du modèle asiatique et la crise de 1997. En identifiant une erreur méthodologique dans ces analyses, nous argumentons que la crise ne résulte pas d'eventuelles faiblesses institutionnelles du modèle sud-coréen. Les caractéristiques institutionnelles, y compris les États développementistes et les grandes entreprises, sont des variantes centrales pour expliquer la grande réussite de la Corée du sud dans les décénnies après 1960 . Ainsi, les difficultés des années 1990 doivent être interprétées comme le résultat d'un processus accéléré de libéralisation et dérèglement économique, mis en oeuvre avant qu'une nouvelle structure de régulation ne soit préparée pour remplacer les formes de coordination en vigueur dans la période précédente. En refusant certaines interprétations de la crise, l'article met en évidence l'importance de reconnaitre les particularités institutionnelles des pays et l'existence de différents types de capitalisme. Le cas sud-coréen, ainsi que celui du Japon, illustre un modèle de capitalisme dont le Developmental State a joué un rôle essentiel, ce qui constitue une variante fondamentale pour expliquer le succès obtenu par la stratégie de développement dans ces pays.

MOTS-CLÉS : Corée du sud; Developmental State; modèles de capitalisme ; crise asiatique ; institutions ; développement. 